\title{
Original article (short paper) \\ Sports Practice and Bone Mass in Prepubertal Adolescents and Young Adults: A Cross-sectional Analysis
}

\author{
Alessandra Madia Mantovani \\ Laboratory of InVestigation in Exercise - LIVE. Scientific Research Group Related to Physical Activity (GICRAF). \\ Universidade Estadual Paulista “Júlio de Mesquita Filho”, Rio Claro, SP, Brasil \\ Manoel Carlos Spiguel Lima \\ Laboratory of InVestigation in Exercise - LIVE. Scientific Research Group Related to Physical Activity (GICRAF). \\ Ricardo Ribeiro Agostinete \\ Laboratory of InVestigation in Exercise - LIVE. Scientific Research Group Related to Physical Activity (GICRAF). \\ Universidade Estadual Paulista “Júlio de Mesquita Filho”, Presidente Prudente,SP, Brasil \\ Igor Hideki Ito \\ Laboratory of InVestigation in Exercise - LIVE. Scientific Research Group Related to Physical Activity (GICRAF). \\ Universidade Estadual Paulista "Júlio de Mesquita Filho”, Rio Claro, SP, Brasil \\ Jamile Sanches Codogno \\ Laboratory of InVestigation in Exercise - LIVE. Scientific Research Group Related to Physical Activity (GICRAF). \\ Universidade Estadual Paulista “Júlio de Mesquita Filho”, Presidente Prudente,SP, Brasil \\ Kyle Robinson Lynch \\ Laboratory of InVestigation in Exercise - LIVE. Scientific Research Group Related to Physical Activity (GICRAF). \\ Universidade Estadual Paulista "Júlio de Mesquita Filho", Rio Claro, SP, Brasil. \\ Rômulo Araújo Fernandes \\ Laboratory of InVestigation in Exercise - LIVE. Scientific Research Group Related to Physical Activity (GICRAF). \\ Universidade Estadual Paulista "Júlio de Mesquita Filho”, Rio Claro, SP, Brasil. \\ Universidade Estadual Paulista “Júlio de Mesquita Filho”, Presidente Prudente,SP, Brasil
}

\begin{abstract}
Aim: To compare bone mass and body composition variables between adolescents engaged in high-impact sports and adults who were sedentary during early life. Method: A cross-sectional study with 155 participants (64 adolescents and 91 adults) aged between 11 and 50 years old. Among the adults, history of sports was evaluated during face-to-face interviews, and information regarding the adolescents' training routines was provided by their coaches. Body composition was evaluated using Dual Energy X-Ray Absorptiometry which provided data about bone mineral density (BMD), bone mineral content (BMC), fat mass (FM), and free fat mass (FFM). Results: Adults who engaged in sports practice during early life had higher values of BMC $(\mathrm{ES}-r=0.063)$, FFM $(\mathrm{ES}-r=0.391)$, and lower values of FM (ES- $r=0.396)$ than sedentary adults. Higher values of BMC (ES- $r=0.063)$ and BMD in lower limbs $($ ES- $r=$ 0.091) were observed in active adolescents. Adolescents engaged in sports and adults who were sedentary in early life presented similar values in all bone variables, FM, and FFM. Conclusions: Sports involvement in early life is related to higher bone mass in adulthood. Adolescents engaged in sports presented similar bone mass to adults who had been sedentary in early life.
\end{abstract}

Keywords: bone health; early sports practice; physical activity; body composition, bone mass

\section{Introduction}

The increased prevalence of osteoporosis in modern society constitutes a public health problem due to its economic impact on health care costs and increase of mortality ${ }^{1,2,3,4}$. Worldwide, up to 9 million new osteoporotic fractures are expected annually with approximately $10.9 \%$ of the total spending of high-cost medications being expenses for drugs acting upon bone structure and mineralization ${ }^{4}$. Studies have shown that adult bone mass is determined by the peak bone mass acquired during childhood and, mainly, adolescence ${ }^{5}$.

During an adolescence growth spurt there is a two-year difference between peak linear growth and peak bone mineral accrual which, among other consequences, can represent where 
the risk of fracture increases due to the discrepancy between body size and bone resistance ${ }^{6,7}$. Additionally, peak height velocity (PHV) is a maturational index of linear growth that denotes the chronological age at which the peak of height is reached. Between the four-year range of PHV ( -2 years and +2 years), there is an accretion of approximately $35 \%$ of all bone mineral content (BMC). The apex of bone mass gain occurs commonly one to two years following PHV.

Since bone mass in adulthood is determined during early life, habits adopted during childhood and adolescence have the potential to affect the risk of osteoporosis in the elderly ${ }^{5}$. During human growth, the bone remodeling process is a dynamic action involving the formation and reabsorption of bone tissue, which is facilitated by behavioral factors, such as nutrition and exercise $^{8}$. In regards to exercise, the skeleton responds positively to biomechanical forces generated by exercise stimulus, in which the osteogenic effect is more evident in the bone sites directly impacted by the activity ${ }^{9,10}$. For instance, adolescent males between the ages of 10 and 18 who were engaged in soccer practice (having a minimum of 3 years of experience in the sport, training for at least 10 hours per week in the previous 6 months, engaging only in physical training associated with each sport discipline, and being at a high competitive level) have higher bone mineral density (BMD) in their proximal femur than swimmers and the control group with sedentary adolescents ${ }^{10}$. Additionally, tennis players have higher BMD in their dominant forearm compared to their non-dominant one ${ }^{9}$.

Scientific research supports that exercise assists BMC when performed during early life and that benefit is maintained until adulthood $^{11,12}$. Furthermore, osteogenic effects of exercise on bone mass/structure seems to be significantly boosted by maturational events ${ }^{6}$. Therefore, it is not clear if the osteogenic effect, as mechanical overloading in the present study, related to exercise can overcome the natural curve pattern of BMC that occurs from adolescence to adulthood.

The purpose of this study was to compare bone mass and body composition variables between adolescents who had not reached PHV and were engaged in high-impact sports to adults who were sedentary during early life. The initial hypothesis states that, despite the obvious difference in size, bone mass of active adolescents is similar to adults who were sedentary during childhood and adolescence.

\section{Methods}

\section{Sample}

This cross-sectional study is composed of 155 participants, which included 64 adults and 91 adolescents. Ages ranged from 30 to 53.6 years' old among the adults and from 12 to 16.1 years' old among the adolescents. This population was provided from two cohort studies conducted in the city of Presidente Prudente (western region of Sao Paulo State, Brazil) by the same research group.

The sample of the present study was accessed from two previous study cohorts developed in the same institution. The first cohort was established from October 2013 to October/ November 2014 (baseline measure; $n=190$ ). The inclusion criteria were: adolescents who were aged 11-17 years and had no limitation for physical activity; only adolescents with negative values of PHV were included. The second cohort was established from August 2013 to August 2014 (baseline measure; $n=122$ ) and the inclusion criteria were: adults between the ages of 30 to 50 years' old, no previous diagnosis of cardiovascular complications (e.g., stroke, heart attack), no diabetes complication (amputation or visual problems), and no limitations for physical activity.

In the first cohort study, 64 adolescents were selected; 39 reported being currently engaged in high-impact sports (soccer, volleyball, and basketball) and 25 reported being sedentary ${ }^{13}$. The adolescents were gathered in 11 different locations, including public or private schools and sport clubs. For the second cohort study, 91 adults were selected; 33 reported being engaged in sports during early life (childhood and adolescence) and 58 reported being sedentary. The adults were gathered at the university and sports clubs located in different geographical regions of the city.

All procedures (questionnaires and body composition assessments) were performed following the same protocols for both cohort studies. The Ethical Research Group of Sao Paulo State University, Presidente Prudente campus, approved both studies (process number for cohort study one: $31.315 / 2012$ and process number for cohort study two: 173.571/2012) and all participants, their parents, and coaches signed a written consent form.

\section{Anthropometrics variables}

Body weight was measured using an electronic scale (Filizzola PL 150 model, Filizzola Ltda, Brazil), and height using a wallmounted stadiometer (Sanny model. American Medical of Brazil Ltda, Brazil). Leg length and sitting-height were also assessed using standardized techniques. These measurements were used to calculate $\mathrm{PHV}^{14}$.

\section{Body composition variables}

The body composition evaluation was performed using Dual Energy X-Ray Absorptiometry (DXA) (Lunar, DPX-MD model, USA) software 4.7, which provided data for BMD $\left(\mathrm{g} / \mathrm{cm}^{2}\right)$, $\mathrm{BMC}(\mathrm{g})$, fat mass (FM), and free fat mass (FFM). The test was performed in a temperature-controlled room with the individuals remaining in a supine position for approximately 10 minutes while the body analysis was performed.

\section{Sports practice}

For adults, their history of sports was evaluated during a faceto-face interview comprised of two questions ${ }^{15-18}$ : "Outside of school, while you were 7-10 years' old, did you engage in any 
organized/supervised sports for at least one-year?" (childhood) and "Outside of school, while you were 11-17 years' old, did you engage in any organized/supervised sports for at least oneyear?" (adolescence).

The adolescents' practice routines (number of sessions per week and time spent per day) were provided by their coaches and the weekly training hours (minutes/week [min / wk]) were estimated. Additionally, the adolescents reported the age at which they began practicing the current exercise for the purpose of calculating the amount of time spent engaged in sports.

\section{Covariates}

The following data were obtained and used to adjust the analyses: (i) gender (male or female); (ii) age (calculated by birth date); (iii) medicine use (any medicine used for the treatment of diabetes mellitus, arterial hypertension, or osteoporosis); (iv) smoking (yes or no); and (v) alcohol consumption in a normal week (any consumption of alcohol was identified [yes or no]).

\section{Statistical Analysis}

Descriptive statistics were composed of median, mean, interquartile range, standard deviation, and $95 \%$ confidence interval $(95 \% \mathrm{CI})$. The analysis of covariance (ANCOVA) comparing the mean differences according to sports in each age group, controlled by potential confounders (Adults: chronological age, gender, smoking, alcohol, and medicine use / Adolescents: chronological age, gender, smoking, alcohol, medicine use, and somatic maturation) in addition to generated estimated means and standard errors are presented. Table 3 presents the ANCOVA comparing means according to sports and age groups controlled by chronological age, gender, smoking, alcohol, and medicine use. These analyses were performed in male and female individuals separately. In all the ANCOVA models, homogeneity of variance was assessed using Levene's test. The measurements of effect size were provided by Eta-Squared (small effect size: 0.010 , medium effect size: 0.060 and large effect size: 0.140$)^{19}$. Statistical significance ( $\mathrm{p}$-value) was set at $p<0.05$ and the statistical software BioEstat (version 5.0) was used to perform all analyses.

\section{Results}

The sample characterization involving the 155 participants from all groups is presented in Table 1 and represents information about age and body composition variables, and for adolescents, PHV and sports practice information is also included.

After controlling for potential confounders, adults engaged in sports during early life had higher values of BMC (medium effect size; ES- $r=0.063$ ), FFM (large effect size; ES- $r=$ 0.391 ), and lower values of body fatness (large effect size;
ES- $r=0.396)$ than sedentary adults. Higher values of BMC (medium effect size; ES- $r=0.063$ ) and BMD in the lower limbs (medium effect size; ES- $r=0.091$ ) were observed in adolescents engaged in volleyball, basketball, and soccer (Table 2).

Regarding bone variables, in both genders BMC and BMD values were similar according to sport practice. However, adults of both genders engaged in sport practice during early life had higher values of the BMC in overall body mass (Table 3). The same pattern has been observed among boys, but not among girls.

Table 1. General characteristics of the adolescents and adults analyzed in the study $(\mathrm{n}=155)$.

\begin{tabular}{|c|c|c|c|}
\hline \multirow[b]{2}{*}{ Variables } & \multicolumn{3}{|c|}{ Descriptive Statistics } \\
\hline & $\begin{array}{c}\text { Median } \\
\text { (IR) }\end{array}$ & Mean (SD) & $(95 \% \mathrm{CI})$ \\
\hline \multicolumn{4}{|l|}{ Adults $(\mathrm{n}=91)$} \\
\hline Age $_{\text {years }}$ & $39.9(10.2)$ & $39.9(5.9)$ & (38.6 to 41.1$)$ \\
\hline DXA-FM $_{(\%)}$ & $32.5(16.3)$ & $33.9(11.3)$ & (31.5 to 36.3 ) \\
\hline DXA-FFM $_{(\%)}$ & $63.9(15.7)$ & $62.2(11.1)$ & (59.9 to 64.5$)$ \\
\hline $\mathrm{BMD}_{\text {whole body }\left(\mathrm{g} / \mathrm{cm}^{2}\right)}$ & $1.279(0.15)$ & $1.283(0.10)$ & $\begin{array}{c}\text { (1.261 to } \\
1.305)\end{array}$ \\
\hline $\mathrm{BMC}_{\text {whole body (g) }}$ & 3009 (713) & $\begin{array}{c}3044.4 \\
(511)\end{array}$ & $\begin{array}{c}\text { (2938.1 to } \\
3150.9)\end{array}$ \\
\hline \multicolumn{4}{|l|}{ Adolescents $(n=64)$} \\
\hline $\operatorname{Age}_{\text {(years) }}$ & $13.3(2.4)$ & $13.4(1.2)$ & (13.1 to 13.7$)$ \\
\hline $\mathrm{PHV}_{\text {(years) }}$ & $-1.63(0.9)$ & $-1.59(0.7)$ & $\begin{array}{c}(-1.77 \text { to } \\
-1.41)\end{array}$ \\
\hline DXA-FM $_{(\%)}$ & $28.3(18.2)$ & $26.8(12.1)$ & (23.7 to 29.8$)$ \\
\hline DXA-FFM $_{(\%)}$ & $67.1(18.1)$ & $68.9(11.7)$ & (65.9 to 71.8$)$ \\
\hline $\mathrm{BMD}_{\text {whole body }\left(\mathrm{g} / \mathrm{cm}^{2}\right)}$ & $1.083(0.17)$ & $1.099(0.09)$ & $\begin{array}{c}(1.099 \text { to } \\
1.124)\end{array}$ \\
\hline $\mathrm{BMC}_{\text {whole body (g) }}$ & $2260(730)$ & $2347(542)$ & $\begin{array}{l}\text { (2211 to } \\
2482)\end{array}$ \\
\hline \multicolumn{4}{|c|}{ Active adolescents $(n=39)$} \\
\hline Previous practice ${ }_{\text {(months) }}$ & $36(53)$ & $51.9(37.3)$ & (39.8 to 64.1$)$ \\
\hline Starting age & $10.3(5.1)$ & $9.8(3.2)$ & (8.7 to 10.8$)$ \\
\hline Practice $_{\text {(minutes/week) }}$ & $480(660)$ & $553.2(336)$ & (444 to 662 ) \\
\hline
\end{tabular}

$\mathrm{IR}=$ interquartile range $; \mathrm{SD}=$ standard-deviation; $95 \% \mathrm{CI}=95 \%$ confidence interval; $\mathrm{BMD}=$ bone mineral density; $\mathrm{BMC}=$ bone mineral content; DXA $=$ dual energy-x-ray absorptiometry; FM = fat mass; FFM = fat free mass. 
Table 2. Bone characteristics (ANCOVA estimated means) of the sample stratified by early and current sports practice, respectively $(\mathrm{n}=155)$.

\begin{tabular}{|c|c|c|c|c|c|c|}
\hline \multirow{3}{*}{ DXA-Variables } & \multicolumn{2}{|c|}{ Adults-Early Sports Practice $(n=91)$} & \multirow{2}{*}{\multicolumn{4}{|c|}{$\begin{array}{c}\text { ANCOVA } \\
\text { (age, gender, smoking, alcohol and medicine use) }\end{array}$}} \\
\hline & \multirow{2}{*}{$\begin{array}{c}\text { No }(\mathbf{n}=\mathbf{5 8}) \\
\text { Mean }(95 \% \mathrm{CI})\end{array}$} & \multirow{2}{*}{$\frac{\text { Yes }(\mathbf{n}=\mathbf{3 3})}{\text { Mean }(95 \% \mathrm{CI})}$} & & & & \\
\hline & & & $\mathrm{F}$ & p-value & ES-r & (qualitative) \\
\hline $\mathrm{BMD}_{\text {whole body }\left(\mathrm{g} / \mathrm{cm}^{2}\right)}$ & $1.266(1.241$ to 1.291$)$ & $1.315(1.281$ to 1.348$)$ & 1.652 & 0.202 & 0.019 & Small \\
\hline $\mathrm{BMC}_{\text {whole body }(\mathrm{g})}$ & $2961(2850$ to 3071$)$ & 3189 (3040 to 3339$)$ & 5.638 & $0.020^{*}$ & 0.063 & Medium \\
\hline DXA-FM $_{(\%)}$ & $38.2(36.3$ to 40.1$)$ & $26.4(24.1$ to 28.9$)$ & 55.187 & $0.001 *$ & 0.396 & Large \\
\hline \multirow[t]{2}{*}{ DXA-FFM $_{(\%)}$} & $58.1(56.4$ to 59.9$)$ & $69.2(66.8$ to 71.5$)$ & 53.940 & $0.001 *$ & 0.391 & Large \\
\hline & \multicolumn{2}{|c|}{ Adolescents-Current Sports Practice $(n=64)$} & \multirow{2}{*}{\multicolumn{4}{|c|}{$\begin{array}{c}\text { ANCOVA } \\
\text { (age, gender, PHV, smoking, alcohol and medicine use) }\end{array}$}} \\
\hline \multirow[t]{2}{*}{ DXA-Variables } & No $(n=25)$ & Yes $(n=39)$ & & & & \\
\hline & Mean $(95 \% \mathrm{CI})$ & Mean $(95 \% \mathrm{CI})$ & $\mathrm{F}$ & p-value & ES-r & (qualitative) \\
\hline $\mathrm{BMD}_{\text {whole body }\left(\mathrm{g} / \mathrm{cm}^{2}\right)}$ & $1.065(1.020$ to 1.110$)$ & $1.122(1.089$ to 1.155$)$ & 3.018 & 0.088 & 0.049 & Small \\
\hline $\mathrm{BMC}_{\text {whole body }(\mathrm{g})}$ & 2138 (1902 to 2373$)$ & 2481 (2309 to 2652 ) & 3.967 & $0.049^{*}$ & 0.063 & Medium \\
\hline DXA-FM $_{(\%)}$ & $30.7(25.1$ to 36.2$)$ & $24.3(20.2$ to 28.4$)$ & 2.409 & 0.126 & 0.039 & Small \\
\hline DXA-FFM $_{(\%)}$ & $65.3(59.9$ to 70.7$)$ & $71.2(67.2$ to 75.1$)$ & 2.182 & 0.145 & 0.036 & Small \\
\hline
\end{tabular}

*p-value < 0.05; DXA = dual energy X-ray absorptiometry; PHV = peak height velocity; $\mathrm{BMD}=$ bone mineral density; $\mathrm{BMC}=$ bone mineral content; $95 \% \mathrm{CI}=$ $95 \%$ confidence interval; ANCOVA $=$ analysis of covariance

Table 3. Bone characteristics (ANCOVA estimated means) of the sample stratified by gender and sport practice $(n=155)$

\begin{tabular}{|c|c|c|c|c|c|c|}
\hline \multirow{3}{*}{ Male $(\mathbf{n}=90)$} & \multicolumn{2}{|c|}{ Adolescents-Current Sports Practice $(n=35)$} & \multicolumn{2}{|c|}{ Adults-Early Sports Practice $(\mathrm{n}=\mathbf{5 5})$} & \multirow{2}{*}{\multicolumn{2}{|c|}{ ANCOVA }} \\
\hline & \multirow{2}{*}{$\begin{array}{c}\text { No }(\mathrm{n}=12) \\
\text { Mean }(95 \% \mathrm{CI})\end{array}$} & \multirow{2}{*}{$\begin{array}{c}\text { Yes }(n=23) \\
\text { Mean }(95 \% C I)\end{array}$} & \multirow{2}{*}{$\begin{array}{c}\text { No }(n=26) \\
\text { Mean }(95 \% C I)\end{array}$} & \multirow{2}{*}{$\begin{array}{c}\text { Yes }(\mathrm{n}=29) \\
\text { Mean }(95 \% \mathrm{CI})\end{array}$} & & \\
\hline & & & & & p-value & ES-r \\
\hline $\mathrm{BMD}_{\mathrm{WB}\left(\mathrm{g} / \mathrm{cm}^{2}\right)}$ & $1.146(1.052$ to 1.241$)$ & $1.192(1.120$ to 1.264$)$ & $1.252(1.198$ to 1.306$)$ & $1.300(1.246$ to 1.355$)$ & 0.070 & 0.084 \\
\hline $\mathrm{BMC}_{\mathrm{WB}(\mathrm{g})}$ & 2718.8 (2305 to 3132$)$ & 2914.7 (2600 to 3228$)$ & 2865.1 (2629 to 3101$)$ & $3137.4(2898$ to 3375$)$ & 0.052 & 0.092 \\
\hline \multirow[t]{2}{*}{$\mathrm{BMC}_{(\% \text { in body mass })}$} & $3.5(2.9$ to 4.1$)$ & $4.4(4.1 \text { to } 4.8)^{\mathrm{A}}$ & $3.5(3.2$ to 3.9$)$ & $4.3(3.9 \text { to } 4.6)^{\mathrm{C}}$ & 0.001 & 0.357 \\
\hline & \multicolumn{2}{|c|}{ Adolescents-Current Sports Practice $(n=29)$} & \multicolumn{2}{|c|}{ Adults-Early Sports Practice $(\mathrm{n}=36)$} & \multirow{2}{*}{\multicolumn{2}{|c|}{ ANCOVA }} \\
\hline \multirow[t]{2}{*}{ Female $(n=65)$} & No $(n=13)$ & Yes $(n=16)$ & No $(n=28)$ & Yes $(n=8)$ & & \\
\hline & Mean $(95 \% C I)$ & Mean $(95 \% \mathrm{CI})$ & Mean $(95 \% C I)$ & Mean $(95 \% C I)$ & p-value & ES-r \\
\hline $\mathrm{BMD}_{\mathrm{WB}\left(\mathrm{g} / \mathrm{cm}^{2}\right)}$ & $1.099(1.024$ to 1.175$)$ & $1.147(1.087$ to 1.207$)$ & $1.200(1.149$ to 1.251$)$ & $1.190(1.121$ to 1.259$)$ & 0.289 & 0.065 \\
\hline $\mathrm{BMC}_{\mathrm{WB}(\mathrm{g})}$ & 2304.7 (1987 to 2622$)$ & $2452.2(2198$ to 2706$)$ & 2606.1 (2389 to 2822$)$ & $2495.5(2204$ to 2786$)$ & 0.443 & 0.047 \\
\hline $\mathrm{BMC}_{(\% \text { in body mass })}$ & 3.7 (3.1 to 4.4$)$ & $4.2(3.7$ to 4.7$)$ & 3.8 (3.3 to 4.2$)$ & $4.6(4.1 \text { to } 5.1)^{\mathrm{C}}$ & 0.004 & 0.211 \\
\hline
\end{tabular}

ANCOVA $=$ analysis of covariance adjusted by chronological age, smoking, alcohol, medicine use, height, and fat free mass. ES- $r=$ eta-squared; BMD $=$ bone mineral density; $\mathrm{BMC}=$ bone mineral content; $95 \% \mathrm{CI}=95 \%$ confidence interval; $\mathrm{A}=$ denotes difference compared to sedentary adolescents; $\mathrm{C}=$ denotes difference compared to sedentary adult in early life.

\section{Discussion}

The main finding of this study showed that adolescents in the initial phase of maturation engaged in sports and adults who were sedentary in early life presented similar values in all bone variables, FM, and FFM. These findings highlight the importance of physical activity / sports activities at an early age because, besides providing benefits to children and adolescents, it appears to exert a protective effect on bone health in adulthood.
The similarities in body composition variables (FM and FFM) among the adolescents can be explained by maturational events that take place from childhood to adolescence which increase adipose tissue ${ }^{20}$. With this information, the role of exercise on adipose tissue (through energy expenditure) from early to later life is crucial in the prevention of obesity in adulthood ${ }^{13}$. However, this particular result could be based upon the cross-sectional design of the study as the relationship between adipose tissue and exercise is based upon the longitudinal approach. Further, 
biological maturation should also be considered due to its effect on FM during human growth ${ }^{21}$.

We found that adults engaged in sports during early life had higher BMC, FFM, and lower FM when compared to sedentary adults. Considering that active adolescents have an increased likelihood of becoming active adults ${ }^{13}$, the effect of exercise on adipose tissue could be used as another pathway to explain the higher BMC in adults who were active during early life. Regular exercise is relevant in preventing obesity and helps control obesity-related inflammation, which in turn decreases bone formation and promotes bone reabsorption ${ }^{22}$. The maintenance of adequate levels of muscle mass is related to biological pathways linked to the prevention of insulin resistance, which negatively affects bone formation ${ }^{23}$.

Another finding revealed that higher values of bone variables were related to sport practice in both adults and adolescents. Scientific literature has linked exercise to bone improvement and recent studies have shown that this relationship is dependent upon the type of activity performed (e.g., resistance, endurance, and plyometric training) ${ }^{24-26}$. In this study, the selection of highimpact sports could have affected bone geometry during early life, independent of biological maturation ${ }^{27}$.

The most relevant finding of this study was the similarity related to bone mass between active adolescents and adults who were sedentary in early life, even after being controlled by potential confounders. Furthermore, all adolescents involved in the study had not reached PHV and therefore, it can be said that the bone mass (density and mineral content) in these adolescents were similar to those presenting with initial phase skeletal maturation. Size and quantity of bone tissue are strongly affected by biological maturation that causes hypertrophy and hyperplasia in different human tissues ${ }^{5,20,23}$. Therefore, the similarities in bone mass between adolescents and adults who had been sedentary in early life is a particularly relevant finding in the prevention of osteoporosis. Scientific literature speculates that high-impact sports in early life can be a beneficial factor for bone growth (directly or mediated by muscle levers $)^{24,28}$, boosting natural development, and improving bone health in adulthood. The biological explanation to support our findings is still unclear; however, adults engaged in sports from early life have increased osteocalcin production $^{29}$ and vascularization of bone tissue ${ }^{30}$ when compared to adults that were sedentary.

The limitations of this study should be recognized. The cross-sectional design does not allow for the establishment of causality statements between dependent and independent variables. It is also not clear whether active adolescents had higher bone mass than the sedentary ones prior to their engagement in sports. Another limitation is the absence of the type of sport practiced by adults during their early stages of life, considering the influence of more vigorous activity of high impact. Finally, the absence of measurements related to bone geometry should be considered in future studies.

In summary, adolescents engaged in high-impact sports presented similar bone mass to adults who had been sedentary in early life.

\section{References}

1. Hannan EL, Magaziner J, Wang JJ, Eastwood EA, Silberzweig SB, Gilbert M, Siu AL. Mortality and locomotion 6 months after hospitalization for hip fracture: risk factors and risk-adjusted hospital outcomes. Jama. 2001; 285(21): 2736-2742.

2. Johnell O, Kanis J. An estimate of the worldwide prevalence and disability associated with osteoporotic fractures. Osteoporos Int. 2006; 17(12): 1726-1733.

3. Kanis JA, Organization WH. (2008). Assessment of osteoporosis at the primary health care level: WHO Collaborating Centre for Metabolic Bone Diseases, University of Sheffield Medical School.

4. Marinho BCG, Guerra LP, Drummond JB, Silva BC, Soares MMS. The burden of osteoporosis in Brazil. Arq Bras Endocrinol Metabol. 2014; 58(5): 434-443.

5. Rizzoli R, Bonjour J, Ferrari S. Osteoporosis, genetics and hormones. J Mol Endocrinol. 2001; 26(2): 79-94.

6. Kemper H, Armstrong N, Van Mechelen W. Physical activity, physical fitness and bone health. Paediatric exercise science and medicine. 2000: 265-272

7. Wren TA, Shepherd JA, Kalkwarf HJ, Zemel BS, Lappe JM, Oberfield S, Gilsanz V. Racial disparity in fracture risk between white and nonwhite children in the United States. J. Pediatr. 2012; 161(6): 1035-1040. e1032.

8. Kim J, Jung M, Hong Y-p, Park J-D, Choi B-S. Physical activity in adolescence has a positive effect on bone mineral density in young men. J Prev Med Public Health. 2013; 46(2): 89-95.

9. Ducher G, Tournaire N, Meddahi-Pellé A, Benhamou C-L, Courteix D. Short-term and long-term site-specific effects of tennis playing on trabecular and cortical bone at the distal radius. J Bone Miner Metab. 2006: 24(6): 484-490.

10. Silva CC, Goldberg TB, Teixeira AS, Dalmas JC. The impact of different types of physical activity on total and regional bone mineral density in young Brazilian athletes. J Sport Sci. 2011; 29(3): 227-234.

11. Karlsson M, Rosengren B. Training and bone-from health to injury. Scand J Med Sci Sports. 2012; 22(4): e15-e23.

12. Lima MCS, Cayres SU, Agostinete RR, Ito IH, Fernandes RA. Estabilidade da prática esportiva durante a infância/adolescência e densidade mineral óssea na idade adulta. Rev. bras. ativ. fis. saúde. $2013 ; 18(4)$ : 445.

13. Van Langendonck L, Lefevre J, Claessens AL, Thomis M, Philippaerts R, Delvaux K, et al. Influence of participation in high-impact sports during adolescence and adulthood on bone mineral density in middle-aged men: a 27-year follow-up study. Am J Epidemiol. 2003; 158(6): 525-533.

14. Mirwald RL, Baxter-Jones AD, Bailey DA, Beunen GP. An assessment of maturity from anthropometric measurements. Med. Sci. Sports Exerc. 2002; 34(4): 689-694.

15. Fernandes RA, Christofaro DGD, Casonatto J, Codogno JS, Rodrigues EQ, Cardoso ML. et al. Prevalence of dyslipidemia in individuals physically active during childhood, adolescence and adult age. Arq Bras Cardiol. 2011; 97(4): 317-323.

16. Fernandes RA, Zanesco A. Early physical activity promotes lower prevalence of chronic diseases in adulthood. Hypertens Res. 2010; 33(9): 926-931. 
17. Lima M, Barbosa MF, Diniz TA, Codogno JS, Freitas Júnior IF, Fernandes RA. Early and current physical activity: relationship with intima-media thickness and metabolic variables in adulthood. Braz J Phys Ther. 2014; 18(5): 462-469.

18. Lima M, Cayres S, Machado-Rodrigues A. Early sport practice promotes better metabolic profile independently of current physical activity. Med Sport. 2014; 18: 172-178.

19. Maher JM, Markey JC, Ebert-May D. The other half of the story: effect size analysis in quantitative research. CBE Life Sci Educ. 2013; 12(3): 345-351.

20. Knittle J, Timmers K, Ginsberg-Fellner F, Brown R, Katz D. The growth of adipose tissue in children and adolescents. Crosssectional and longitudinal studies of adipose cell number and size. J Clin Invest. . 1979; 63(2): 239.

21. Coelho-e-Silva MJ, Ronque ERV, Cyrino ES, Fernandes RA, Valente-dos-Santos J, Machado-Rodrigues A, et al. Nutritional status, biological maturation and cardiorespiratory fitness in Azorean youth aged 11-15 years. BMC public health. 2013; 13(1): 1.

22. Cao JJ. Effects of obesity on bone metabolism. J Orthop Surg Res. 2011; 6(1): 1 .

23. Bayol S, Bruce C, Wadley G. Growing healthy muscles to optimise metabolic health into adult life. J Dev Orig Health Dis. 2014; 5(06): 420-434.

24. Barbieri D, Zaccagni L. Strength training for children and adolescents: Benefits and risks. Coll Antropol. 2013; 37(2): 219-225.

25. Faigenbaum AD, Kraemer WJ, Blimkie CJ, Jeffreys I, Micheli LJ, Nitka M, Rowland TW. (Youth resistance training: updated position statement paper from the national strength and conditioning association. J Strength Cond Res. 2009; 23: S60-S79.

26. Gregov C, Šalaj S. The Effects of Different training modalities on bone mass: a Review. Kineziologija. 2014; 46(Supplement 1): 10-29.

27. Ferry B, Lespessailles E, Rochcongar P, Duclos M, Courteix D. Bone health during late adolescence: effects of an 8-month training program on bone geometry in female athletes. Joint Bone Spine. 2013; 80(1): 57-63.
28. Tan VP, Macdonald HM, Kim S, Nettlefold L, Gabel L, Ashe $\mathrm{MC}, \mathrm{McKay}$ HA. Influence of physical activity on bone strength in children and adolescents: a systematic review and narrative synthesis. J Bone Miner Res. 2014; 29(10): 2161-2181.

29. Elloumi M, Ounis OB, Courteix D, Makni E, Sellami S, Tabka $\mathrm{Z}$, Lac G. Long-term rugby practice enhances bone mass and metabolism in relation with physical fitness and playing position. J Bone Miner Metab. 2009; 27(6): 713-720.

30. Ducher G, Courteix D, Meme S, Magni C, Viala J, Benhamou C. Bone geometry in response to long-term tennis playing and its relationship with muscle volume: a quantitative magnetic resonance imaging study in tennis players. Bone. 2005; 37(4): 457-466.

\section{Acknowledgments}

The São Paulo Research Foundation (FAPESP) process numbers 2012/18001-0 and 2013/06963-5)

\section{Corresponding author}

Alessandra Madia Mantovani

Address: Roberto Simonsen Avenue, 310, Centro Universitário, Presidente Prudente, SP, Brazil

Email: leka_indy@hotmail.com

Manuscript received on April 25, 2016

Manuscript accepted on May 31, 2016

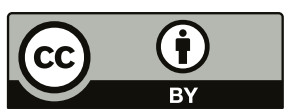

Motriz. The Journal of Physical Education. UNESP. Rio Claro, SP, Brazil - eISSN: 1980-6574 - under a license Creative Commons - Version 3.0 